\title{
PEDAGOGIA E EDUCAÇÃO DOS COSTUMES NUM ANTIGO LIVRO INFANTIL: DER STRUWWELPETER
}

\author{
Maria da Conceição Lima de Andrade ${ }^{*}$ \\ Melita Bona* \\ Gilson R. DE M. Pereira ${ }^{* * *}$
}

Vertrauen ist gut, aber Kontrolle ist besser.

"Confiança é bom, mas controle é melhor"

(adágio alemão).

\begin{abstract}
RESUMO: A partir da análise de um livro infantil originalmente publicado na Alemanha em 1845, Der Struwwelpeter, de autoria de Heinrich Hoffmann, o presente estudo apreende os modos pelos quais as pedagogias difusas atuam sobre os agentes, conformandolhes tanto a estrutura dos sentimentos quanto os esquemas práticos de percepção, apreciação e ação necessários à integração do indivíduo ao mundo social. Considera-se que o estudo de livros infantis constitui ocasião privilegiada para desvelar as formas pelas quais as instituiçōes educativas contribuem para a adesão dos indivíduos à ordem social. Conclui-se que a pedagogia do livro mencionado favorece a subordinação da criança à vida urbana e estimula a autorregulação infantil. Isso é feito pela inculcação de uma "crença prática" voltada a regular ritmos e relaçóes da criança, bem como a transferir um certo número de "metáforas práticas" destinadas a possibilitar à criança a adesão a um mundo social marcado pelo risco.
\end{abstract}

Palavras-chave: Der Struwwelpeter. Literatura infantil. Educação dos costumes. Violência simbólica. Pedagogia difusa.

* Doutora em Ciências Sociais e professora no Programa de Pós-Graduação em Educação da Universidade Regional de Blumenau (FURB).E-mail: mconceicao@furb.br

** Mestre em Educação pelo Programa de Pós-Graduação em Educação da FURB. E-mail: melitab@terra.com.br

*** Doutor em Educação e professor no Programa de Pós-Graduação em Educação da FURB. E-mail: gilsonmp@furb.br

Educ. Soc., Campinas, vol. 30, n. 106, p. 131-149, jan./abr. 2009

Disponível em <http://www.cedes.unicamp.br> 
Pedagogy and Custom education in AN Old CHILdRen's BOOK: DER STRUWWELPETER

ABSTRACT: Based on a children's book originally published in Germany in 1845, Der Struwwelpeter, by Heinrich Hoffman, the present study grasps how diffuse pedagogies act on the agents, moulding both the structure of their feelings and the practical perception, appreciation and action schemes necessary to the integration of individuals in the social world. We understand that studying children's books is a privileged occasion to unveil the ways through which educational institutions contribute to the adhesion of individuals to the social order. We thus come to the conclusion that the pedagogy of Der Struwwelpeter is intended to subordinate children to urban life and stimulates an early selfregulating attitude. That is attained by impressing a "practical belief" meant to regulate children's rhythms and relations, as well as to transfer a number of "practical metaphors" destined to enable their adhesion to a risk-marked world.

Key words: Der Struwwelpeter. Children's literature. Custom education. Symbolic violence. Diffuse pedagogy.

\section{Introdução}

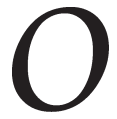

texto a seguir apresenta os resultados de um estudo destinado a apreender os modos pelos quais as pedagogias difusas, quer dizer, implícitas e não intelectuais, conformam nos agentes a estrutura dos sentimentos e as disposiçóes geradoras, ou seja, os esquemas práticos de percepção, apreciação e ação necessários à integração lógica e moral do indivíduo ao mundo social. Se, como afirma Bourdieu (1987, p. 257), "a ação pedagógica deve sempre transmitir, além de um conteúdo, a afirmação do valor desse conteúdo", e se isso é mais verdadeiro particularmente nas inculcações pedagógicas cujo conteúdo não é outro senão o próprio valor inculcado, então se é conduzido à hipótese segundo a qual o estudo sociológico de livros infantis, manuais de bom comportamento, tratados das virtudes, entre outros, justamente por serem obras capazes de operar a colagem quase completa entre conteúdo e valor do conteúdo, constitui ocasiāo privilegiada para desvelar as formas mediante as quais as instituiçóes educativas (família e escola), ao legitimar e disseminar valores - bons comportamentos, modos corretos, preceitos a serem 
seguidos, modelos de virtude -, contribuem, cada uma a seu modo, para a adesão dos indivíduos à ordem social.

Além disso, e como complemento, a análise sociológica de textos como os anteriormente mencionados também constitui oportunidade para trazer à luz os mecanismos, acionados pelas pedagogias difusas, necessários à incorporação, pelos agentes, das disposiçōes capazes de orientar a prática e dotá-la de sentido prático (Bourdieu, 1980). Por sua vez, o estudo das pedagogias difusas, cujo efeito propriamente simbólico é exercido sem prática específica, sem institucionalização e sem objetivos conscientemente postos por "sujeitos" conscientes, auxilia na tarefa de desvelar, relativamente aos processos educativos, aquilo que Malinowski (1978, p. 29) chamou de "os imponderáveis da vida real", isto é, toda a trama de ações e reações, muitas vezes invisíveis, que conformam os indivíduos e revelam como estes são capazes de ação inteligível e coerente, muito embora esta não seja necessariamente o produto de deliberações racionais ou teóricas (Bourdieu, 1980). As pedagogias difusas aqui referidas diferem das pedagogias dos pedagogos precisamente por não serem pensadas e organizadas segundo um "plano de conjunto", por não serem codificadas, mas funcionarem segundo o modus operandi assistemático do encorajamento, da emulação e da imitação (Wacquant, 2002).

\section{O referente empírico}

O material empírico submetido à análise é um antigo livro infantil, Der Struwwelpeter (O menino desleixado), de autoria do doutor Heinrich Hoffmann. Para tanto, consultou-se uma edição em alemão, lançada pela Pestalozzi Verlag, sem data e local de publicação, ilustrada em cores, com $20 \times 27 \mathrm{~cm}$, de 22 páginas, cotejada com as versões eletrônicas em francês e inglês (Hoffmann, 2007a; 2007b) e com duas recentes edições em inglês, impressas pela Dover (Hoffmann, 1995) e pela Reclams Universal-Bibliotechek (Hoffmann, 1994), sendo, esta última, a famosa tradução de Mark Twain. Der Struwwelpeter, com o título de "João Felpudo", foi publicado no Brasil pela Editora Laemmert, no final do século XIX, e teve oito edições. Posteriormente, uma versão de Guilherme de Almeida, ilustrada por Dorca, foi publicada pela Editora Melhoramentos. A primeira edição feita nesta 
casa editorial é de 1942 e a última, a quinta, é de 1950, atingindo a tiragem de 36.000 exemplares (São Paulo, 2007).

O livro, originalmente publicado na cidade de Frankfurt em 1845 e, atualmente, na $568^{a}$ edição alemã, consta de nove historietas rimadas em verso, ilustrativas de ações não desejadas - o menino que maltrata os animais ("A história do malvado Frederico"), a menina que acidentalmente ateia fogo às vestes ("A triste história da caixa de fósforos"), os meninos que zombam de um negrinho ("A história dos meninos negros"), o rapaz que caça ("A história do famoso caçador"), o menino que chupa os polegares ("A história de Conrado, o chupador de polegares"), o menino que não quer tomar sopa ("A história de Kaspar da sopa"), o menino que não pára quieto à mesa ("A história de Felipe, o inquieto"), o menino que não olha por onde anda ("A história de João, o cabeça-de-vento") e o menino desobediente carregado pelo vento ("A história de Roberto, o voador") -, ações merecedoras de corretivo exemplar. Este vem sempre sob forma inesperada, quase abrupta, mais ou menos trágica (morte, perda de dedos, entre outras) e, simultaneamente, mais ou menos engraçada.

Especializado nos cuidados às crianças - também uma disciplina em plena invenção na primeira parte do século XIX -, Hoffmann imagina o Struwwelpeter e cria o primeiro livro cômico, em sua forma moderna, destinado às crianças de 3 a 6 anos de idade. Esse pequeno livro ilustrado compreende nove pequenas histórias, todas inspiradas numa desventura nascida da vida cotidiana, mas para cuja resolução o autor faz intervir o nonsense. (Feuerhahn, 2007)

Escritas, sobretudo, para divertir e entreter a criança pequena, as histórias são dirigidas para o desenvolvimento moral da infância, expresso no controle de impulsos considerados inadequados (recusar-se à alimentação, não parar quieto à mesa), na correção de más ações (maltratar e caçar animais) ou maus costumes (chupar o dedo, não cortar e não pentear os cabelos, deixar as unhas crescerem), na previsão dos perigos manifestos ao não se seguir os conselhos familiares (queimar-se, sofrer as consequências de sair de casa sob tempestade) e no combate aos preconceitos (ridicularizar os diferentes).

As condições imediatas de produção da obra anteriormente mencionada são assim descritas pelo autor: 
Nas proximidades do Natal de 1844, quando meu filho mais velho estava com 3 anos de idade, fui à cidade comprar um livro ilustrado para presenteá-lo no Natal. O livro deveria estar de acordo com a capacidade de compreensão da faixa etária deste pequeno ser humano. Mas o que encontrei? Longas histórias ou ridículas coletâneas de figuras, histórias moralistas, que iniciavam e terminavam com preâmbulos repletos de advertências, tais como: "A criança comportada deve ser honesta", ou: "Crianças comportadas devem manter-se limpas" etc. Finalmente, ao encontrar um "Foliobuch" com ilustrações de um banco, uma cadeira, uma panela e muitas outras coisas, de seres animados e inanimados, um verdadeiro repertório ilustrado do mundo, em que junto a cada ilustração viase escrito muito claramente: a metade, um terço ou um décimo do seu tamanho natural, a minha paciência se esgotou (...). Mas, ao chegar em casa naquele dia, eu trazia comigo um livro. Entreguei-o à minha esposa, dizendo: "Eis aqui o livro para o menino". Ela pegou o livro e exclamou surpresa: "Mas isto é um caderno de folhas em branco!". "Sim, e nós vamos transformá-lo em um livro.". (Hoffmann, s/d., contracapa)

Embora tendo criado Der Struwwelpeter apenas para consumo doméstico, Hoffmann cede aos apelos de amigos e o publica: "de todos os lados fui solicitado a editar e publicar o livro (...) a princípio rejeitei a idéia (...) a forma como isso aconteceu foi involuntária e meio a contragosto" (Hoffmann, s/d., contracapa). O livro, então, conheceu uma fortuna crítica inesperada:

E foi assim que esta obra caseira, pouco ambiciosa, repentinamente ganhou o mundo, fazendo sua viagem - acho que posso dizer - ao redor do mundo, alcançando hoje, após 31 anos, a sua $100^{a}$ edição. Até o momento chegaram até mim traduções para os seguintes idiomas: inglês, holandês, dinamarquês, sueco, russo, francês, italiano, espanhol e uma em português (para o Brasil). Também gostaria de comentar sobre o especial sucesso inicial que o livrinho obteve na própria cidade de Frankfurt. (Idem, ibid.)

\section{Sucesso editorial e atualizações modernas}

O sucesso do livro pode ser avaliado pela quantidade de referências atualmente disponíveis na rede mundial de computadores (na produção brasileira, em periódicos educacionais especializados, menção a Der Struwwelpeter pode ser encontrada em Zuin [2003]; também, em 
página brasileira na internet [Lago, 2007]). Diversos endereços eletrônicos discutem a questão pedagógica presente no Struwwelpeter, muitos deles analisando detalhadamente as histórias. Isso pode ser visto, por exemplo, na enciclopédia eletrônica Wikipedia (2007). Sob o título Interpretação psicológica, esta página comenta que, recentemente, o Struwwelpeter foi descoberto pelas clínicas de psicologia e de psiquiatria para jovens, uma vez que suas histórias descrevem certos tipos de distúrbios que se manifestam na infância: distúrbio da atenção, acompanhado da hiperatividade, como no caso de "A história de Felipe, o inquieto" (cf. também Shansis \& Grevet, 2007), oposta à "A história de João, o cabeça-de-vento", enquadrado como "sonhador", isto é, sem hiperatividade, porém com a atenção muito reduzida. Supõe-se que o próprio Hoffmann apresentava certo distúrbio de atenção. Em todos os casos, como médico, esses distúrbios lhe eram familiares. A mesma página apresenta obras e títulos inspirados no livro de Hoffmann, como, por exemplo, o Struwwelhitler, o livro de histórias nazistas do Doutor Schrecklichkeit, uma ácida paródia inglesa publicada em 1941 por Robert e Philip Spence. O livro foi relançado em 2005, por ocasião da comemoração dos 60 anos da queda do regime nazista, com os textos originais em inglês e tradução para o alemão.

Na página eletrônica, Der Struwwelpeter - eine Sitten - und Kulturgeschichte (Der, 2007), são apresentados os imitadores do Struwwelpeter, uma série de tentativas de copiar ou inverter o sucesso e a pedagogia do Dr. Hoffmann, ora intensificando a "pedagogia do chinelo", ora chamando atenção para o conflito com o autoritarismo. Em 1864, surge a primeira contrapartida feminina ao Struwwelpeter, Die Schreiliesel (Maricota gritalhona ou A menina gritalhona), uma coletânea alegre e educativa para crianças em torno dos 8 anos de idade, de autoria do Dr. Ernst. As histórias são engraçadas e muito coloridas, uma espécie de paródia do Struwwelpeter, com cenas do tipo: "A menina gritalhona quer andar sozinha, mas cai"; "A menina gritalhona que não quer beber seu leite” etc. Os finais são bem mais drásticos do que os de Hoffmann, como por exemplo: "o pai agarrou a menina gritalhona, que não quer se lavar, e a mergulhou numa tina", ou "varreu seus brinquedos [jogou fora] quando ela não os quis arrumar". Em 1870 , surgiu outra versão feminina, Die Struwwelliese", com certo sucesso; em 1896, este livro comemorou sua $40^{a}$ edição e está até hoje disponível no mercado editorial. Muito tempo depois, em oposição ao 
Struwwelpeter original, surgiria em 1970 o Anti-Struwwelpeter, de autoria de Friedrich Karl Waechter, uma crítica aos tabus sociais e às práticas educativas consideradas repressivas e inadequadas ao século XX. Por sua vez, Der Struwwelpeter von heute (1914), obra de Fritz Stern, é um livro em quadrinhos para adultos. Aqui o Struwwelpeter aparece como símbolo do "homem natural", do movimento da juventude e do neorromantismo, quebrando os moldes culturais antigos, opondo-se a todo tipo de regulamentação da liberdade de espírito do jovem. Este Struwwelpeter é amigo dos animais e se alegra com a "natureza divina".

\section{A educação moral no Der Struwwelpeter}

O livro infantil alemão, segundo observa Walter Benjamin, nasceu com o Iluminismo, como parte integrante de um programa de formação humanitária. "Se o homem era piedoso, bom e sociável por natureza, então poderia ser possível fazer da criança, ser natural por excelência, o homem mais piedoso, mais bondoso e mais sociável" (Benjamin, 1984, p. 49). Dotado de um conjunto de atributos simbólicos, a seguir descritos, Der Struwwelpeter constitui modelo de uma forma hoje já desaparecida de educar os costumes e ensinar moralidade a crianças. Por um lado, anacrônico, em razão da rudeza e do caráter fatalista das narrativas, além da dimensão do que hoje poderia ser chamado de "educação pelo terror", identificável ao longo de todo o texto, Der Struwwelpeter é, por outro lado, atual quando comparado com livros infantis recentes, no que diz respeito aos propósitos de educação dos costumes e, por extensão, de educação moral.

$\mathrm{Na}$ introdução de $O$ livro das virtudes para crianças, seleção de textos voltados à edificação infantil, o organizador faz notar que:

(...) a educação moral - a educação do espírito e da mente para o bem envolve diversos aspectos. Envolve regras e preceitos - o que se deve e o que não se deve fazer no convívio com o outro. Envolve a prática reiterada de bons hábitos. E envolve ainda o exemplo dos adultos, que, por meio das atitudes que adotam no cotidiano, demonstram às crianças o apreço que têm pela retidão. (Bennett, 1997, p. 5-6)

Provavelmente, este esboço de programa de educação infantil seria subscrito por Heinrich Hoffmann, muito embora, bem entendido, a estrutura da sensibilidade dos alemães cultos de meados do século 
XIX não partilhasse o apreço pelo "gesto adocicado" presente nas narrativas infantis, sobretudo as atuais, como as organizadas por Bennett. Para Benjamin (1984, p. 53), este gesto adocicado "corresponde não à criança, mas às concepções distorcidas que se tem dela”. Com outras palavras, conquanto inserido no movimento que estende à educação das crianças e ao livro infantil o ideário do Iluminismo, processo correlativo ao que Norbert Elias (1993, p. 207-210) chamou de "difusão da pressão pela previdência e pelo autocontrole", Der Struwwelpeter é estruturado numa forma tal que não faz concessões, pela aspereza e quase brutalidade das historinhas, a uma literatura infantil agradável e digestiva, razão pela qual parece aos contemporâneos deste início de século XXI como desprovido de sensibilidade (uma constante na crítica atual ao livro é caracterizá-lo como "humor negro"; fala-se também em "black pedagogy").

Produzido numa época da narrativa infantil onde não se faz economia de realismo, Der Struwwelpeter não evita os problemas da vida, nem tampouco as coerções advindas da convivência social. Distinguese, por conseguinte, do tipo de narrativa infantil "fora de perigo" (Bettelheim, 2001, p. 15), na qual são eludidos os problemas suscitados pelos confrontos no cotidiano. Escrito, conforme notificado na edição consultada, com o objetivo de criar um livro infantil que não estivesse dotado das características mais marcantes das admoestações dirigidas às crianças pelos adultos da época, consideradas excessivamente severas por Hoffmann (s/d., contracapa) - "'Filho, se você não se comportar, o limpador de chaminé vem e te pega' ou: 'Filho, se você comer demais, vem o doutor e te dá um remédio amargo ou te aplica sangue-sugas'” -, Der Struwwelpeter aparentemente se situa, no entanto, no que diz respeito à sensibilidade adulta relativamente à educação da criança pequena, a meio caminho daquilo que se poderia chamar de realismo medieval, com seu apelo às descrições mais cruas e à produção de histórias sumamente terrificantes, e do pathos das atuais histórias infantis, mais inclinadas ao já mencionado "gesto adocicado". Seria talvez suficiente submetê-lo a uma comparação sistemática, a montante, com os contos tradicionais, de origem russa, protagonizados pela bruxa Baba Iaga, como, por exemplo, "Vassilissa, a bela" (cf. Os mais belos..., 1993, p. 75-93), ou mesmo com o clássico "Joãozinho e Mariazinha” dos irmãos Grimm (cf. Os contos..., 1989, p. 79-90), contemporâneos de Hoffmann, histórias seguramente marcadas pela 
sensibilidade medieval, tanto na problemática como na forma (a solidão, o bosque, a escuridão, o casebre, a bruxa comedora de gente), e, a jusante, com as histórias infantis atuais, para reter essa característica de transição de Der Struwwelpeter.

\section{Educação dos costumes e autocontrole}

Neste estudo, faz-se a opção segundo a qual as possibilidades objetivas disponíveis para os autores de livros infantis na Alemanha em meados do século XIX orientam as tomadas de posição, funcionando "como uma espécie de sistema comum de coordenadas que faz com que, mesmo que não se refiram uns aos outros, os criadores contemporâneos estejam objetivamente situados uns em relação aos outros" (Bourdieu, 1996, p. 54). Isso quer dizer, ainda seguindo Bourdieu (1996, p. 64), que o projeto criador dos autores de livros infantis na época e lugar aqui considerados depende da "percepção das possibilidades disponíveis" capazes de orientar praticamente as opções simultaneamente estéticas e pedagógicas. Por essa lógica, é pertinente procurar as propriedades simbólicas de Der Struwwelpeter não nas eventuais idiossincrasias do autor, porém no estado da produção do livro infantil à época e no que esse estado deve tanto à constelação das preocupaçóes pedagógicas então mais legítimas quanto à estrutura da sensibilidade inscrita, sob a forma de esquemas práticos de classificação, percepção e apreciação, no habitus das classes cultivadas do período.

Der Struwwelpeter deve todas as suas propriedades às condições sociais nas quais foi produzido. Como anteriormente mencionado, o livro de Hoffmann é tributário de uma etapa do processo civilizador do Ocidente, na qual "ocorreu o fortalecimento do autocontrole e a permanência das compulsões - a inibição de paixôes e o controle de pulsóes - impostos pela vida no centro dessas redes [de interdependências]" (Elias, 1993, p. 207). Disso decorre que a pedagogia difusa de Der Struwwelpeter está inteiramente voltada a operar a conversão das coerções sociais externas em autorrestrições ou autorregulações da criança. Ou seja, a inculcar na infância disposições destinadas ao controle dos impulsos (da conduta e das emoçôes) e ao desenvolvimento do espírito de previsão. Isso fica claro já na epígrafe do livro, posta na capa, uma exortação à educação dos costumes e ao uso de modos civilizados: 
Vejam só, ele está aqui. / Vergonha! O menino desleixado! / De ambas as mãos, / Não permitiu que lhe cortassem as unhas / Durante quase um ano; / Não permitiu que lhe penteassem os cabelos. / Vergonha! Exclamam todos: / O asqueroso menino desleixado!

A já mencionada conversão das coerções sociais externas em autorrestrições ou autorregulações é tão mais importante de realçar quando se observa que Hoffmann, médico, membro das classes cultivadas, estava seguramente predisposto, pela posição social ocupada e pelo habitus correspondente, a ver no controle da conduta o trunfo decisivo na manutenção de seus privilégios e no cumprimento de suas funções sociais. Um breve apontamento biográfico do autor evidencia o que se quer dizer:

Heinrich Hoffmann nasceu em 1809, em Frankfurt am Main, filho de Jacob Hoffmann, arquiteto, e Marianne Caroline (Lausberg) Hoffmann. Estudou Medicina nas Universidades de Heidelberg, Halle e também em Paris. Após a graduação em 1833, trabalhou como clínico-geral em sua cidade natal. Em 1840, casou com Therese Donner. Entre 1844 e 1851, ensinou anatomia. De 1851 a 1888, Hoffmann foi diretor do Hospício Público de Frankfurt am Main. Durante esses 37 anos se dedicou ao tratamento psiquiátrico de pacientes e lançou as bases para um novo hospital municipal, que foi construído entre 1859 e 1864 . Publicou Der Struwwelpeter em 1845, sob título Lustige Geschichten und drollige Bilder mit 15 schön kolorirten Tafeln für Kinder von 3-6 Jahren. $\mathrm{O}$ nome Struwwelpeter apareceu na terceira edição alemã. Hoffmann também publicou poesia, humor e sátira, vários outros livros para crianças e escritos sobre Medicina e Psiquiatria. Hoffmann morreu a 20 de setembro de 1894. (Heinrich, 2007)

Sem ser intencionalmente normativo (ver o desagrado causado no Dr. Hoffmann pelas histórias moralistas, "que iniciavam e terminavam com preâmbulos repletos de advertências, tais como: 'a criança comportada deve ser honesta', ou: 'crianças comportadas devem manter-se limpas' etc" [Hoffmann, s/d., contracapa]), Der Struwwelpeter, no entanto, é um livro de educação moral: tudo se passa como se o autocontrole visasse, embora o autor não necessariamente tivesse isso em mente, a transformar a ordem doméstica em ordem moral, esta última no sentido durkheimiano de ordem regrada, "consistindo de regras de conduta sancionadas" (Durkheim, 1995, p. 42). Por um lado, isso é operado pelo controle das pulsões, termo aqui entendido no sentido psicanalítico de tendências permanentes, em geral inconscientes, 
que dirigem a atividade do indivíduo, como, por exemplo, a libido sexual, e, por outro, por meio da coerção pela previdência, entendida como disposição para o cálculo, o mais das vezes tácito, das consequências engendradas pela ação.

A propriedade simbólica mais característica da pedagogia de Der Struwwelpeter é a utilização de um modo não-eufêmico de comunicação com as crianças. Com efeito, a violência simbólica da inculcação, no livro do Dr. Hoffmann, apoiando-se quase sempre apenas na autoridade pedagógica familiar (pai, mãe), não dissimula sua verdade objetiva de violência. É assim no controle das pulsões, exemplificado por "A história de Conrado, o chupador de polegares": Conrado é advertido pela mãe para não chupar os dedos, pois do contrário o alfaiate viria cortá-los. Tão logo esta sai de casa, o menino não controla suas pulsões e, conforme previsão materna, tem os dedos decepados ("Eis que a porta se abre / e com saltos rápidos / o alfaiate se lança sala adentro / em direção ao menino chupador de polegares / e então, oh infelicidade!, fazendo clip e clap / corta-lhe os polegares / com a grande e afiada tesoura / Ai! Conrado grita muito!"). Mesmo nas relações de comunicação apoiadas em evento físico, por vezes trágico ou cruel, obtém-se o efeito propriamente simbólico de educação dos costumes, considerando que "não há relação de força, por mecânica que seja, que não exerça também um efeito simbólico" (Bourdieu \& Passeron, 1992, p. 24). A eficácia simbólica é obtida pela mistura de não-eufemização com nonsense.

O sucesso alcançado pelo livro de Hoffmann, quer dizer, sua rentabilidade simbólica, deve-se também, segundo o próprio autor, a "feliz estilo e forma dos versos". Observa-se que as rimas, de fácil assimilação, obedecem à sequência lógica dos acontecimentos e, em algumas histórias, têm sua fluência incrementada pelo uso de onomatopéias, como, por exemplo, na anteriormente mencionada história de Conrado, o chupador de polegares: "Fort geht die Mutter und Wupp! (expressa o som do gesto do polegar sendo levado à boca), den Daumen in den Mund / Bauz! (o ruído da porta sendo aberta) Da geht die Türe auf, / (...) Weh! Jetzt geht es klipp und klapp" (som da tesoura cortando os dedos). Assim como em "A triste história da caixa de fósforos": "Miau! Mio! Miau! Mio! / wirf’s weg! Sonst brennst du lichterloh". Neste caso, a onomatopéia do miado dos gatos rima com "lichterloh", num refrão que se repete algumas vezes. Parte-se, aqui, do pressuposto 
de que as histórias eram lidas em voz alta pelos adultos, considerando o fato de o público-alvo ser constituído de crianças na faixa etária de 3 a 6 anos, dando-se a aprendizagem, ou melhor, a memorização, por meio da métrica e da concordância sonora da rima (memória musical). Parece que Hoffmann se antecipou na "pedagogia das rimas".

O desenvolvimento da sensibilidade cultivada ou urbanidade, bons modos acionados pela contenção das pulsões, também se faz presente em Der Struwwelpeter. Em "A história dos meninos negros" aparece claramente o preconceito, a molestação e a falta de respeito, que têm como desenlace o castigo, "arcar com as consequências", aliás, uma tônica na educação alemã. Um ditado muito utilizado nesta pedagogia afirma: "Wer nicht hören will muss fühlen", ou seja, "quem não quer ouvir [os conselhos] será obrigado a sentir".

Por sua vez, integrante do citado processo civilizador das sociedades ocidentais, o desenvolvimento do espírito de previdência está associado ao controle e à noção de risco. No mundo moderno, racionalizado,

(...) procura-se controlar o futuro calculando os riscos (...) esta nova interpretação participa da transformação da cadeia de causalidade. $\mathrm{O}$ acontecimento infeliz aparece então como o resultado de uma série de decisões inadequadas. A responsabilidade humana ocupa seu lugar na fatalidade. (Poulain, 2004, p. 98)

A previdência, associada à noção de risco, é bastante evidenciada em "A triste história da caixa de fósforos", na qual a menina Pauline desobedece aos pais ao brincar com fósforos ("Ah! Esta caixa, como é bela! / Eu vou me divertir, diz ela. / Eu acenderei os palitos, / como faz a mamãe algumas vezes"). Embora os gatos façam-lhe lembrar os conselhos paternos para não fazer isso ("E os gatos Minz e Maunz / A ameaçam com suas patas / E dizem, o dedo em riste: / Teu pai te avisou! / Miau! Larga isso, / Ou tu vais te queimar toda"), Pauline termina por atear acidentalmente fogo às vestes ("Oh! Má hora! Eis que a chama / atinge o vestido: tudo se queima. / As mãos, os cabelos, tudo queimava. / A criança inteira ardia!"). A história conclui com os gatos chorando diante das cinzas da menina ("E de Pauline, oh! Sorte funesta! / dois sapatinhos, eis o que resta. / E perto das cinzas da criança / Os gatos sentam-se chorando").

O deslocamento das coerçôes externas para o âmbito interno das disposições, capazes de antecipar o que vai ocorrer antes mesmo do fato 
eventual, é simbolizado, na história de Pauline, pela ausência dos pais na cena, substituídos que foram pelos gatos, metáfora da consciência moral ainda não inteiramente desenvolvida. A lógica da coerção pela previdência instaura-se, assim, na seguinte sequência: é perigoso para a criança brincar com fósforos (pressuposto da regra), logo, a criança não deve brincar com fósforos (regra); porém, o circuito moral só se completa quando a criança, independentemente de sua vontade e mesmo sem a presença ostensiva dos legitimadores da regra (os pais), não brinca com fósforos em virtude da força da regra em si mesma (moralidade). $\mathrm{O}$ efeito obtido por essa pedagogia prática é a capacidade internalizada tanto de previsão de um acidente potencial (queimar-se) como das consequências da ação (morrer). Considerando, hoje, os dados estatísticos de acidentes domésticos com crianças pelo menos momentaneamente postas na ausência de adultos, constata-se a atualidade, mais de um século depois de publicado, do tema proposto por Der Struwwelpeter.

Também em "A história de Kaspar da sopa", a previdência e o risco estão presentes. Pelo caráter exemplar da pedagogia difusa identificável no livro, a história de Kaspar merece ser transcrita na íntegra:

O Kaspar era muito saudável, / um menino forte e gorducho, / tinha bochechas rosadas e viçosas; / tomava a sopa de maneira comportada. / Porém, certa vez começou a gritar: / "Eu não quero tomar a sopa! Não! / Eu não vou tomar minha sopa! / Não! A minha sopa eu não tomo!” / No dia seguinte, ora, veja só! / Ele já estava bem mais magro. / E novamente pôs-se a gritar: / "Eu não quero tomar a sopa! Não! / Eu não vou tomar minha sopa! / Não! A minha sopa eu não tomo!" / No terceiro dia, ai que desgraça! / Como Kaspar está magrinho e fraco! / Mas eis que a sopa é posta na mesa, / Logo começou a gritar: / "Eu não quero tomar a sopa! Não! / Eu não vou tomar minha sopa! / Não! A minha sopa eu não tomo!" / E, finalmente, no quarto dia / Kaspar está magro como um fio. / Pesava, possivelmente, 15 gramas; / E no quinto dia estava morto.

$\mathrm{Na}$ história de Kaspar, ao que tudo indica, trata-se de assegurar a socialização do menino por meio da identidade cultural da família, controlando a ambivalência prazer/desprazer no âmbito alimentar (um exemplo empírico desse controle pode ser visto na análise feita por Cicourel [2004] de uma microssituação familiar mãe-criança à mesa). Se, como observa Poulain (2004, p. 105), "comer é um ato que impõe fazer escolhas, decidir, mas também assumir riscos objetivos e simbólicos", então se é levado à conclusão de que a inserção nos gostos e nas 
regras alimentares familiares é inculcada pela pedagogia difusa de Der Struwwelpeter acionando, assim como na história de Pauline, o par constituído pela previdência e pelo risco.

\section{A atualidade de um livro inatual}

Os arbitrários pedagógicos são recebidos diferencialmente pelas distintas classes e frações de classe, ou, por outras palavras, o reconhecimento e a incorporação das exortações pedagógicas dependem da congruência entre o conteúdo da mensagem e as condições sociais e o modo de vida dos receptores (cf. a análise da produtividade do trabalho pedagógico em Bourdieu \& Passeron, 1992, p. 43-64). Esse enunciado sociológico, tão frequentemente ignorado, sobre as condições de possibilidade de todas as pedagogias serve como preventivo epistemológico necessário à ruptura com as mitologias pedagógicas, tão caras ao mundo escolar, dos enunciados performativos válidos para todos indistintamente, e, simultaneamente, de uma segunda ruptura, dessa vez com a noção falsamente erudita que estabelece a atualidade, o moderno e o contemporâneo segundo a ordem da cronologia, como operador capaz de tornar compreensível o fato de livros como Der Struwwelpeter permanecerem, simultaneamente, atuais e inatuais no século XXI.

Inatuais, nas sociedades diferenciadas, para os grupos e as camadas sociais que, por meio das atualizações pretéritas do habitus, já incorporaram a seu modo de vida o autocontrole, fazendo deste o núcleo de um programa difuso de transmissão familiar de padrões sociais legítimos. Para tais grupos e camadas, visto que já dispõem do autocontrole como capital incorporado, ou seja, como disposição estruturada e estruturante, permanente e transferível de geração a geração, Der Struwwelpeter tem pouco ou quase nada a acrescentar. Porém, a prática do autocontrole não é tão difundida no espaço social quanto se supõe, mesmo hoje em dia. É truísmo, reforçado pelas páginas dos jornais, afirmar que o autocontrole está desigualmente distribuído entre as diferentes classes e os grupos sociais. Isso sugere a atualidade de Der Struwwelpeter e da forma pedagógica pela qual se reveste, considerando o papel educativo do medo ("A criança e o adolescente jamais aprenderiam a controlar o próprio comportamento sem o medo instilado por outras pessoas" [Elias, 1993, p. 269]). 
De fato, seria preciso ler a notícia "Abuso sexual termina em morte de garoto de 7 anos", entre tantas outras, para identificar em crianças contemporâneas traços de personalidades sociais do passado, cuja característica mais notável é a incontinência das paixões:

O crime chocou a comunidade [Três Barras, norte de Santa Catarina] pelo envolvimento de meninos tão novos com a violência sexual e pela forma brutal como Rafael [7 anos] foi morto - afogado nas águas de um rio. (...) $\mathrm{O}$ menino [13 anos] acusado pelo crime (...) disse que tinha oferecido um rádio de pilha a Rafael em troca de relações sexuais. Em princípio, Rafael aceitou a oferta. Eles chegaram a tirar parte das roupas, em cima de um barranco que dava no rio e começaram a fazer sexo anal. Mas, segundo o depoimento da criança, Rafael teria pedido para parar. Então o menino maior se recusou a entregar o rádio e eles começaram a trocar socos. Rafael foi empurrado no barranco de cerca de quatro metros e ameaçou contar tudo aos pais. Logo após, o menino o empurrou no rio e esperou que ele se afogasse, indo para casa em seguida. Rafael estudava no CAIC do bairro. A mãe, que é diarista, conta que nunca deixava o filho mais novo sair sozinho, mas na quinta-feira foi trabalhar e deixou os seis filhos sob os cuidados do pai, desempregado. (Jornal de Santa Catarina, 2005, p. 26)

Considerando que as famílias investem tão mais duradouramente no trabalho pedagógico de controle das pulsões e previdência quanto maiores as expectativas relativamente à posição que ambicionam ocupar na estrutura das funçôes sociais (Elias, 1993), então se compreende por que as famílias das camadas populares tendem ao laxismo nos controles das pulsões. Coagidas, pela violência inerte das necessidades e urgências, ao realismo e a não apostar demasiado numa forma de controle social cuja rentabilidade lhes escapa, as famílias das classes e dos grupos populares tendem a não estabelecer as redes internas de admoestações e incitações que conformam os habitus e regulam as estratégias cotidianas adequadas aos arbitrários mais legítimos (escolares, culturais, sociais, entre outros). Tudo sugere, no caso anteriormente noticiado, assim como em outros semelhantes, sobretudo em razão de condições de existência (mãe diarista, seis filhos, pai desempregado) mais favoráveis à descontinuidade das experiências, à instabilidade das emoções e ao descontrole das ações, que a pedagogia difusa das famílias nessas específicas condições sociais não consegue acionar o trabalho prolongado de inculcação cujo término é proporcionar à criança pequena o desenvolvimento do eu autorregulado, com o consequente 
ingresso na esfera da moralidade, no sentido durkheimiano antes referido. Desnecessário dizer que o fracasso deste trabalho pedagógico familiar de incitações difusas resulta amiúde em exclusão escolar, quando não em consequências trágicas.

\section{Algumas considerações complementares}

Para explicitar inteiramente as propriedades simbólicas de $D e r$ Struwwelpeter, seria preciso observar, mais uma vez, as condiçôes sociais de produção, vale dizer, as condições de produção do produtor. Heinrich Hoffmann, certamente, apreciava os valores citadinos do modo de vida urbano das classes cultivadas alemãs do século XIX. Mencionar a cumplicidade entre habitus e posição social é bastante para, retomando as análises de Weber e Marx sobre as relaçóes entre o desenvolvimento do capitalismo, o ambiente urbano e a construção do espírito de previsão, afirmar que a pedagogia difusa de Der Struwwelpeter constitui uma espécie de transfiguração das propriedades de posiçãao do autor (profissional específico, citadino, membro das elites). De fato, considerando, como o faz Weber, que a urbanização contribui decisivamente para a racionalização da conduta, mormente das classes sociais dominantes, e, como o faz Marx, que a estrutura temporal da atividade produtiva no capitalismo abre a possibilidade de calculabilidade e previsibilidade dos agentes, e considerando também as correspondências entre estrutura social e formas simbólicas, então se pode concluir que a pedagogia de Der Struwwelpeter está voltada a favorecer a subordinação da criança à vida urbana - com todos os seus inusitados perigos, com as inúmeras coações impostas pelas redes muito estreitas de relações - e a estimular desde cedo a "idolatria da cultura", na forma de controle das pulsōes e previdência, oposto imediato à "idolatria da natureza" (descontrole, cólera, incontinência etc.) favorecida pelas características mais marcantes da vida rural e camponesa.

"A artimanha da razão pedagógica", observa Bourdieu (1980, p. 117), "reside precisamente no fato de extorquir o essencial sob aparência de exigir o insignificante". No caso de Der Struwwelpeter, o essencial, isto é, tirar partido da autorregulação infantil, sob formas de controle das pulsōes e de previdência, para inculcar na infância as disposições exigidas pela socialização primária, ou seja, para fazer incorporar na criança pequena a ordem social sob a forma de hexis corporal, encontra sua 
eficácia simbólica no fato de possuir todas as aparências de somenos (não chupe o dedo, não brinque com fósforo, preste atenção onde pisa etc.). Destarte, a pedagogia de Der Struwwelpeter inculca uma espécie de "crença prática" voltada a regular tempo, espaço, ritmos e relações da criança, assim como a transferir, sem eufemismo e sem o já citado "gesto adocicado", um certo número de "metáforas práticas" (as historinhas, os versos, as rimas) destinadas, uma vez incorporadas como esquemas operatórios, a possibilitar à criança a adesão a um mundo social marcado pelo risco:

No mundo moderno, aqueles que são mais felizes na tranquilidade doméstica [como as crianças] talvez sejam os mais vulneráveis aos demônios que assediam esse mundo; a rotina diária dos parques e das bicicletas, das compras, do comer e limpar-se, dos abraços e beijos costumeiros talvez não seja apenas infinitamente bela e festiva, mas também infinitamente frágil e precária; manter essa vida exige talvez esforços desesperados e heróicos, e às vezes perdemos. Ivan Karamazov diz que, acima de tudo o mais, a morte de uma criança lhe dá ganas de devolver ao universo o seu bilhete de entrada. Mas ele não o faz. Ele continua a lutar e a amar; ele continua a continuar. (Berman, 1987, p. 14)

Talvez esta seja também a lição do doutor Heinrich Hoffmann.

Recebido em setembro de 2007 e aprovado em maio de 2008.

\section{Referências}

ABUSO sexual termina em morte de garoto de 7 anos. Jornal de Santa Catarina, Blumenau, v. 33, n. 10, p. 369, 11 e 12 jun. 2005.

BENJAMIN, W. Reflexões: a criança, o brinquedo, a educação. São Paulo: Summus, 1984.

BENNETT, W.J. (Org.). O livro das virtudes para crianças. Rio de Janeiro: Nova Fronteira, 1997.

BERMAN, M. Tudo que é sólido desmancha no ar: a aventura da modernidade. São Paulo: Cia das Letras, 1987.

BETTELHEIM, B. A psicanálise dos contos de fadas. 15. ed. Rio de Janeiro: Paz \& Terra, 2001. 
BOURDIEU, P. Le sens pratique. Paris: Minuit, 1980.

BOURDIEU, P. A economia das trocas simbólicas. 2. ed. São Paulo: Perspectiva, 1987.

BOURDIEU, P. Razões práticas: sobre a teoria da ação. Campinas: Papirus, 1996.

BOURDIEU, P.; PASSERON, J.-C. A reprodução: elementos para uma teoria do sistema de ensino. 3. ed. Rio de Janeiro: Francisco Alves, 1992.

CICOUREL, A.V. L'habitus et le pouvoir symbolique comme processus sociocognitifs: quelques suggestions empiriques. In: BOUVERESSE, J.; Roche, D. (Org.). La liberté par la connaissance: Pierre Bourdieu (1930-2002). Paris: Odile Jacob, 2004.

OS CONTOS DE GRIMM. Trad. do alemão de Tatiana Belinski; ilustração Janusz Grabianski. São Paulo: Paulus, 1989.

DURKHEIM, E. Leçons de sociologie. Paris: PUF, 1995.

ELIAS, N. Formação do Estado e civilização. In: EliAs, N. O processo civilizador. Rio de Janeiro: Zahar, 1993. v. 2.

HOFFMANN, H. Der Struwwelpeter. [S. 1.]: Pestalozzi, [s.d.]

HOFFMANN, H. Der Struwwelpeter auf englisch. Nachdichtung von Mark Twain. Stuttgart: Philipp Reclam jun. GmbH \& Co., 1994.

HOFFMANN, H. Struwwelpeter in English translation. Nova York: Dover, 1995.

OS MAIS BELOS CONTOS DA RÚSSIA. Ilustração Mariana Belieyeva. Lisboa: Civilização, 1993.

MALINOWSKI, B.K. Argonautas do Pacífico ocidental: um relato do empreendimento e da aventura dos nativos nos arquipélagos da Nova Guiné Melanésia. 2. ed. São Paulo: Abril Cultural, 1978. (Os Pensadores).

POULAIN, J.-P. Sociologia da alimentação. Florianópolis: UFSC, 2004.

WACQUANT, L. Corpo e alma: notas etnográficas de um aprendiz de boxe. Rio de Janeiro: Relume Dumará, 2002. 
ZUIN, A.A.S. Sobre a atualidade dos tabus com relação aos professores. Educação \& Sociedade, Campinas, v. 24, n. 83, p. 417-428, ago. 2003.

\section{Referências eletrônicas}

FEUERHAHN, N. Pierre l'ébouriffé: l'énigme d'une figure surréaliste. Disponível em: <melusine.univ-paris3.fr/astu/Feuer.pdf>. Acesso em: 5 set. 2007.

HEINRICH HOFFMANN (1809-1894): pseudonyms Reimerich Kinderlieb, Heinrich Kinderlieb, Peter Struwwel, Heulalius von Heulenburg, Polykarpus Gastfenger, and Zwiebel. Disponível em: <http://www.kirjasto.sci.fi/hhoffman.htm>. Acesso em: 5 set. 2007.

HOFFMANN, H. Pierre l'ébouriffé. Disponível em: <http://www. struwwelpeter.com/SP/_pierre.php>. Acesso em: 5 set. 2007a.

HOFFMANN, H. Slovenly Peter. Disponível em: <http://www.fln. vcu.edu/struwwel/furpete.html>. Acesso em: 5 set. $2007 \mathrm{~b}$.

LAGO, A. Struwwelpeter de Heinrich Hoffmann. Disponível em: <http:// www.angela-lago.com.br/1Hoffmann.html>. Acesso em: 5 set. 2007.

SÃO PAULO. Centro de Referência em Educação. A escola pública e o saber, literatura infantil. Disponível em: <http://www.crmariocovas. sp.gov.br/obj_a.php?t=infantil01>. Acesso em: 5 set. 2007.

SHANSIS, F.; GREVET, E. Histórico do Transtorno de Déficit de Atenção/Hiperatividade. Disponível em: <http://www.sinodal.com.br/fotos/ 2004/palestra_shansis/historico.ppt>. Acesso em: 5 set. 2007.

DER STRUWWEELPETER - eine Sitten - und Kulturgeschichte. Disponível em: <http://www.bikonline.de/histo/struwwel1.html>. Acesso em: 5 set. 2007.

WIKIPEDIA DIE FREIE ENZYKLOPÄDIE. Struwwelpeter. Disponível em: <http://de.wikipedia.org/w/index.php?title=Struwwelpeter \&printable=yes $>$. Acesso em: 5 set. 2007. 